Successful strategies for including adults with an intellectual disability into a research study using interpretative phenomenological analysis (IPA)

Mary Drozd, Darren Chadwick, Rebecca Jester

\title{
Abstract
}

Background: Adults with intellectual disabilities are not regularly recruited as participants in health research which may be due to perceptions regarding their inability to participate meaningfully with or without significant support and anticipated difficulty in gaining ethical approval because of issues around consent and mental capacity. This means that the voices of people with an intellectual disability are often missing within health research and their experiences and views are unexplored.

Aim: To share successful strategies for accessing, recruiting and collecting data from a purposive sample of adults with an intellectual disability using interpretative phenomenological analysis (IPA).

Discussion: Interpretative Phenomenological Analysis was a person-centred, flexible and creative approach to adopt. Meaningful collaboration with people with intellectual disabilities, their families, carers, advocacy group managers, specialists within intellectual disability services and research supervisors was vital to the success of conducting this study. Practical strategies for including people with an intellectual disability in a study from the perspective of a novice researcher, an outsider to the field of intellectual disability, have been shared. A limitation is that participants were not included in all stages of the research process.

Conclusion: Inclusion of participants with an intellectual disability in research studies is important and achievable for healthcare researchers. A framework to support 
researchers outside of the specialist field of intellectual disabilities has been presented.

Implications for practice: Adults with intellectual disabilities often receive poor healthcare and have poorer outcomes which is perpetuated if their input into research is not facilitated. People with intellectual disabilities make valuable contributions to the evidence base; personal views and perceptions of healthcare are important if health services are to meet individual needs.

Key words: Intellectual/learning disability, participant recruitment strategies, interpretative phenomenological analysis, inclusion.

\section{Introduction and background to the study}

People with an intellectual disability do not have the same access to and quality of care that people without an intellectual disability are afforded and there is evidence that mainstream health services have difficulty in providing an equitable service for people with intellectual disabilities compared with the general population (Mencap, 2007; Emerson and Baines, 2011; lacono et al., 2014). This is particularly evident in acute hospital care and the deleterious impact of sub-standard care and treatment of people with intellectual disabilities has led to premature and unnecessary deaths as highlighted in a number of reports (Heslop et al., 2013; National Health Service England (NHSE), 2020).

There are many definitions of intellectual disability; the Royal College of Nursing (RCN) (2017, p. 1) state it is, 'a lifelong condition, resulting in a reduced intellectual ability and thus difficulty with everyday tasks'. An intellectual disability affects the way 
a person understands information and includes a lifelong difficulty with learning new skills and understanding information (NHSE, 2017).

In 2006, the United Nations Convention on the Rights of Persons with Disabilities, endorsed by the United Kingdom, stated the rights of disabled people to 'enjoyment of the highest standards of health without discrimination on the basis of disability' (article 25). However, there is still evidence of inequitable access to health care including the speciality of orthopaedics with Michael (2008) highlighting that people with intellectual disabilities were at increased risk of poor bone health but despite this, assessment of bone health is often not undertaken. Moreover, there was an underutilisation of the preventative services related to musculoskeletal conditions and injuries amongst people with intellectual disabilities (Srikanth et al., 2011). Burke et al. (2019) demonstrated that the prevalence of poor bone health in people with intellectual disabilities was substantial implying an increased risk of fracture due to reduced skeletal integrity. Furthermore, Finlayson (2011) and Finlayson et al. (2010; 2014) reported that people with intellectual disabilities sustain more injuries, falls and accidents than the general population.

Kinnear et al. (2018) illustrated that the most prevalent physical health conditions affecting people with intellectual disabilities included osteoporosis, bone deformity and musculoskeletal pain. Whilst it is known that people with intellectual disabilities have a higher prevalence of musculoskeletal injuries and conditions than the general population, there was no published research related to their experiences of orthopaedic or trauma hospital care. This was the rationale for investigating the 
experiences of people with intellectual disabilities in orthopaedic and trauma in-patient settings.

Crook et al. (2015) purport that people with intellectual disabilities have been excluded from participating in research for numerous reasons including: to protect them as a vulnerable population, a perceived inability to participate meaningfully in research, ethical considerations, practicalities and restrictions imposed by 'gate keepers'.

The aim of this paper is to share the strategies used by a novice researcher (the first author, henceforth referred to as 'the researcher') from an orthopaedic nursing background to overcome difficulties with the recruitment and inclusion of adults with an intellectual disability into an interpretative phenomenological analytical (IPA) research study. An overview of IPA is provided as it is not widely used within nursing. Although not all nurses will undertake research or conduct research with people with intellectual disabilities, the focus is on inclusion of people with intellectual disabilities who may want to share their experiences and have a right to have their voices heard (Goldsmith and Skirton, 2015; Department of Health and Social Care, 2019).

\section{Aims of the study}

Study aims were, to 'give a voice' to people with intellectual disabilities who have not traditionally taken part in research, along with 'making sense' and offering an interpretation of the gathered data to inform the current evidence base (Larkin and Thompson, 2012, p. 101).

\section{The study approach}

Interpretative Phenomenological Analysis (IPA) is a qualitative, hermeneutic phenomenological approach (Finlay, 2011) that was first proposed by Jonathan Smith in 1996 who argued for an experiential approach in psychology. IPA was chosen due 
to its commitment to explore, describe, interpret and situate the participant's sense of their experiences (Smith et al., 2009). The theoretical perspectives of IPA include phenomenology, hermeneutics and idiography (Smith et al., 2009); see Table 1 for an overview. This approach provided the most appropriate context for facilitating and 'including the perspectives of vulnerable people' (Gibbs and Read, 2010, p. 233).

Table 1: The theoretical underpinnings of IPA (Smith et al., 2009)

\begin{tabular}{|l|l|}
\hline Phenomenological & $\begin{array}{l}\text { Bracketing of past knowledge and presuppositions is } \\
\text { required whilst collecting the data }\end{array}$ \\
\hline Hermeneutic & Data collection is exploratory and participant led \\
\hline Idiographic & $\begin{array}{l}\text { The researcher engages in a 'double hermeneutic', } \\
\text { in that the researcher is making sense of the } \\
\text { participant's sense making }\end{array}$ \\
\hline & $\begin{array}{l}\text { Person-centred approach allowing flexibility and } \\
\text { creativity }\end{array}$ \\
\hline
\end{tabular}

\section{An overview of the study}

The study sought to answer the following question: How do adults with an intellectual disability describe their orthopaedic or trauma hospital experiences? The study investigated how people with intellectual disabilities make sense of their orthopaedic or trauma hospital experiences using a person-centred approach that was developed by McCormack and McCance (2010) and this was congruent with the theoretical underpinnings of IPA (Smith et al. 2009; Ravitch and Riggan, 2017). The literature review and findings are reported elsewhere. Tables 2, 3 and 4 illustrate the issues that were encountered and the practical strategies required by the researcher who was an outsider to the specialist field of intellectual disabilities. Furthermore, the tables 
illuminate the specific ethical and methodological considerations that led to successfully enabling people with intellectual disabilities to participate in the study.

\section{Recruitment of participants}

\section{The researcher as an outsider}

There was difficulty recruiting people with intellectual disabilities and it took over a year to gain access to potential participants. Sydor (2013) discussed the terms, "hard to reach' and 'hidden' which seem very appropriate here. 'Hard to reach' describes a population that is difficult for researchers to access and 'hidden' refers to a population with no defined limits such that the exact size cannot be known (Sydor, 2013, p. 35). The researcher had not worked in the specialist field of intellectual disability and therefore was an 'outsider', which made access more difficult.

Participants were recruited through the managers of local self-advocacy groups for people with intellectual disabilities and through national organisations that work with people with intellectual disabilities and their healthcare professional members. The advocacy group managers were facilitators as well as gatekeepers to the study, which was important for the safeguarding of people with intellectual disabilities. The managers discussed the study within their advocacy groups to establish if anyone was interested which enabled potential participants to make an informed choice about their involvement in the study.

During a national intellectual disability conference, the researcher was introduced by a colleague to an advocacy group manager. Following an informal discussion, the manager agreed that she would ask her group if anyone would like to be involved in 
the study. Nicholson, Colyer and Cooper (2013) asserted that gatekeepers were most likely to promote participation when benefits to the participant or to themselves were easily identified. Crook et al. (2015) believe that clearly outlining the rationale for the research and giving time to address concerns may encourage greater support from managers who act as gatekeepers. This meeting was instrumental in gaining access to potential participants.

Personal meetings with other self-advocacy group managers were organised and this facilitated the recruitment of people with intellectual disabilities who had experienced orthopaedic or trauma hospital care. For one group, the researcher was asked to attend and help with activities for a couple of months so that people with intellectual disabilities could feel comfortable to ask questions about the study and decide if they wanted to be involved. This was an effective strategy and helped the researcher become more acquainted with the whole group. Although ethical approval was granted by the university, a further approval process was required with the governing body of one of the self-advocacy groups. See Table 2. 
Table 2: A practical framework for the researcher as an outsider to the field of intellectual disabilities

\begin{tabular}{|l|l|}
\hline $\begin{array}{l}\text { 'Researcher as an } \\
\text { outsider' } \\
\text { considerations }\end{array}$ & Practical strategies \\
\hline Participant identification & $\begin{array}{l}\text { The researcher must initiate and establish a good } \\
\text { working relationship with colleagues working in the field } \\
\text { of intellectual disabilities }\end{array}$ \\
\hline Access to participants & $\begin{array}{l}\text { Allow sufficient time for facilitators, such as advocacy } \\
\text { group managers, carers or specialists in the field of } \\
\text { intellectual disabilities, to explain the study in an } \\
\text { accessible way to people with intellectual disabilities }\end{array}$ \\
\hline $\begin{array}{l}\text { Recruitment of } \\
\text { participants }\end{array}$ & $\begin{array}{l}\text { Collaborate with the facilitators such as advocacy } \\
\text { group managers, carers and specialists in intellectual } \\
\text { disabilities } \\
\text { Plan prior meetings and embrace the opportunities to } \\
\text { meet potential participants in a safe environment with } \\
\text { others e.g. in an advocacy group meeting. }\end{array}$ \\
$\begin{array}{l}\text { Allow time for building a rapport and trust with the } \\
\text { group of potential participants as well as time for } \\
\text { questions about the study } \\
\text { A separate time must be arranged for the interview if } \\
\text { there is agreement to proceed and participate to allow } \\
\text { time to think about consent }\end{array}$ \\
\hline Communication & $\begin{array}{l}\text { Training and education on how to communicate } \\
\text { effectively with people with an intellectual disability } \\
\text { should be undertaken by the researcher from outside } \\
\text { the field of intellectual disabilities } \\
\text { Reasonable adjustments in line with the Equality Act } \\
\text { (2010) should be made throughout all phases of the } \\
\text { study } \\
\text { Use of accessible information is essential, for example, } \\
\text { using easier read information and/or pictorial resources }\end{array}$ \\
\hline
\end{tabular}




\section{Specific ethical considerations}

\section{Communication and consent}

Communication is a particularly important component of the consent process for all people and people with intellectual disabilities were given opportunities to discuss the study with others, such as the local advocacy group managers, their carers and families (McCarthy, 1998). The consent process began with a discussion with the participant to ensure that the participant understood the rationale for the study and what was expected of them along with how the data would be captured, stored and used (Llewellyn and Northway, 2008). A study day on communicating with people with intellectual disabilities was undertaken with a national organisation and this helped to prepare the researcher for recruitment, consenting and data collection processes. The easier read participant information sheet and consent form were designed specifically with short simple sentences supported in a pictorial format with the expertise of people with intellectual disabilities. Hollins et al. (2017) suggest that pictorial resources reduce anxiety and empower the person with an intellectual disability.

\section{Confidentiality and Anonymity}

Although confidentiality and anonymity were considered from the outset, an area that had not been incorporated into the research design was that participants may wish to co-present their experiences at conferences. Manning (2009) highlighted that in contrast to ethical requirements for anonymity, some people with intellectual disabilities may want their names to be known. However, if there was a possibility that identification of the participants in the study may expose them to certain risks or harm, then this must be considered. Nuwagaba and Rule (2015) recognised that tensions occur in research ethics if people with intellectual disabilities are viewed through the 
lens of the medical model of disability which would want to protect the 'rights' of people with intellectual disabilities to anonymity due to the belief that people with intellectual disabilities may be unable to make informed rational decisions. Conversely, if people with intellectual disabilities are viewed though a social and human rights model of disability as having agency and right to make decisions for themselves, the reality can mean that people with intellectual disabilities may increasingly want to speak for themselves (Nuwagaba and Rule, 2015). Therefore, whilst it may be appropriate for some groups of people, such as people with severe intellectual disabilities, to receive special ethical considerations, it is important that this does not undermine the autonomy and self-efficacy of other groups of people with intellectual disabilities (Nuwagaba and Rule, 2015).

Some months after an interview with a participant, an advocacy group manager contacted the researcher because a participant wanted to share her experiences at a local conference where the researcher was due to present the findings. Discussions were held with authors two and three, one of whom was a member of the university ethics committee, and it was agreed that the participant had a right to present her experiences; support was provided by the advocacy group and the authors to facilitate this. Another participant was aware that the findings were being presented at an international nurses' conference and she requested to co-present and shared her powerful story during a plenary session.

Although the dominant research discourse classifies people with intellectual disabilities as vulnerable (Silverman, 2011), the two participants who sought to share their experiences in a public domain understood that this would mean that their identity 
would be known. Their wishes and voices were respected and they co-presented at two different conferences. See Table 3.

Table 3: A practical framework relating to specific ethical considerations

\begin{tabular}{|l|l|}
\hline Specific ethical & Practical strategies \\
\hline Consent & $\begin{array}{l}\text { The researcher requires a clear understanding of the } \\
\text { Mental Capacity Act and how to apply it in research } \\
\text { practice } \\
\text { Develop the participant information sheet and consent } \\
\text { form with people with intellectual disabilities using } \\
\text { easier read and/or pictorial, accessible information to } \\
\text { aid comprehension }\end{array}$ \\
\hline anonymity & $\begin{array}{l}\text { Provide clear, easier read and/or pictorial accessible } \\
\text { participant information about how confidentiality and } \\
\text { anonymity will be maintained } \\
\text { Consideration in the initial design of the study that } \\
\text { participants may wish to co-author or co-present their } \\
\text { data and how that marries with ethical requirements for } \\
\text { confidentiality and anonymity. }\end{array}$ \\
\hline Safety and support & $\begin{array}{l}\text { Researcher must be guided by family/paid carers, } \\
\text { advocacy group managers and/or specialists working in } \\
\text { intellectual disabilities regarding maintaining participant } \\
\text { safety and provision of individualised support for } \\
\text { participants }\end{array}$ \\
\hline
\end{tabular}

\section{Specific methodological considerations}

\section{Data collection}

A semi-structured interview format was chosen as people with intellectual disabilities

can benefit from some level of structure when being interviewed (Gilbert, 2004). Although a practice interview was undertaken with a colleague, on reflection a pilot interview with a person with an intellectual disability would have been beneficial. Herron et al. (2015) advocated planning prior meetings with participants in order to 
establish and build a rapport and level of trust; this also enabled the researcher to judge the communication level of participants. The same researcher interviewed each participant and time was allocated to establish a rapport and build trust before gaining valid consent prior to taking part in the interview. The interview questions were open and broad and a visual hospital communication book (Mencap, 2016) was available as a prompt.

Engaging with each participant through an individualised approach was crucial to success (Herron et al., 2015). One participant with dysarthria communicated using electronic mail very effectively so this additional method of data collection was adaptively included. On reflection, some of the participants might have benefited from using traffic light cue cards during the interview (see Table 4) (Tajuria et al., 2017).

\section{Location of interview}

The effect of the location of interviews on data collection has been highlighted as the meanings attached to the location of an interview can influence the research process (Braun and Clarke, 2013). That said, each participant's safety and wellbeing was of paramount importance and the location of the interview was agreed with the participant and the advocacy managers or family/paid carer as well as the researcher's supervisors. The locations were at advocacy group meeting places with the manager in sight or at the person's home with the carer present. The date and times of the interview were important to the participant so as not to clash with activities they enjoyed. 


\section{Inclusive participatory research}

Inclusive research is described as research with, by and for people with intellectual disabilities and other groups and not research done to them (Garcia Iriarte et al., 2014; Nind and Vinha, 2014). The extent to which research is inclusive or participatory is dependent upon the degree to which people with intellectual disabilities are in control as co-researchers (Northway, 2000). The study design was inclusive and can be positioned in the participatory tradition on the inclusive continuum as it enabled people with intellectual disabilities to participate meaningfully (Walmsley et al., 2017). That said the design could have been more inclusive if people with an intellectual disability were involved in the development of the research question, collection of data as well as in the analysis and dissemination of the findings of the study (Bigby et al., 2014). This is a limitation of the study and an area of further development for the researcher. Furthermore, Barr et al. (2019 page 538) highlight that research funders now often require evidence of 'patient public involvement' (PPI) and this is considered as good practice in research studies. See Table 4. 
Table 4: A practical framework relating to specific methodological

\section{considerations}

\begin{tabular}{|c|c|}
\hline $\begin{array}{l}\text { Specific } \\
\text { methodological } \\
\text { considerations }\end{array}$ & Practical strategies \\
\hline $\begin{array}{l}\text { Data collection tool - } \\
\text { semi-structured interview }\end{array}$ & $\begin{array}{l}\text { Flexibility and adaptations to the data collection tool } \\
\text { must be considered to enable credible data collection } \\
\text { e.g. a semi-structured interview can be supported by } \\
\text { pictorial aids, e.g. the Hospital Communication Book } \\
\text { developed by Mencap (2016) } \\
\text { Undertake a pilot interview with a person with an } \\
\text { intellectual disability } \\
\text { Participants may want another person with them as a } \\
\text { support during the interview process } \\
\text { Colour coded cards - red, amber and green can be } \\
\text { used during the data collection process as a way for } \\
\text { participants to stop the interview (red), time to think } \\
\text { (amber) and ready to continue with the interview } \\
\text { (green) } \\
\text { Flexibility to include and accommodate another form of } \\
\text { data collection such as via electronic mail if participant } \\
\text { has difficulty with verbal articulation }\end{array}$ \\
\hline Choice and respect & $\begin{array}{l}\text { Participants should be offered a choice of dates and } \\
\text { times for the interview to cause least disruption to their } \\
\text { other activities. } \\
\text { Consideration of participants' individual needs and } \\
\text { accommodations that are required }\end{array}$ \\
\hline Location of the interview & $\begin{array}{l}\text { Participant safety is of paramount importance and } \\
\text { location of the interview must be negotiated and agreed } \\
\text { with the participant and their carer/supporter as well as } \\
\text { other members of the research team }\end{array}$ \\
\hline $\begin{array}{l}\text { Inclusive participatory } \\
\text { design of the study }\end{array}$ & $\begin{array}{l}\text { People with intellectual disabilities should be central to } \\
\text { the study; the research question, design, interpretation, } \\
\text { analysis and dissemination of the findings should } \\
\text { involve people with intellectual disabilities } \\
\text { Feedback of the findings to the participants in a user- } \\
\text { friendly format. } \\
\text { Facilitation of co-presentation of findings }\end{array}$ \\
\hline
\end{tabular}




\section{Discussion}

IPA was found to be a flexible and creative methodological approach (Smith et al., 2009). The findings were analysed using a double hermeneutic cycle incorporating the perspectives of the participants and the researcher. These findings have been disseminated at conferences with participants and they have informed national competencies for orthopaedic and trauma practitioners (Royal College of Nursing, 2019) which underpins current and future training and education.

The second author has many years of experience and expertise in research with people with intellectual disabilities and their carers. Collaboration with colleagues from the specialist field of intellectual disabilities led to the researcher being introduced to the facilitators and gatekeepers who had access to people with intellectual disabilities, e.g. advocacy group managers. Meeting the facilitators, gatekeepers, carers and people with intellectual disabilities to discuss the study resulted in successful access, recruitment and active participation of people with intellectual disabilities by using reasonable adjustments (Northway et al., 2014). The advocacy group managers and family/paid carers were vital in sharing the information about the study, discussing it over time and preparing participants for the interview. Data collection methods must accommodate and support participant's individual needs which IPA facilitated (Smith et al., 2009).

A limitation of the study was that the participants were not included in all stages of the research process. Conducting high quality research whilst simultaneously including people with intellectual disabilities at each stage of the research process requires considerable planning and the development of a number of facilitation skills (Garcia Iriarte et al., 2014; Nind and Vinha, 2014). This recognised as an area for the future development of the researcher. 


\section{Conclusion}

Facilitating and enabling people with intellectual disabilities to make a contribution to research are important to the planning and development of services that are responsive to individual needs. Practical strategies employed in the study have been shared, specifically pertaining to access, recruitment and data collection with people with intellectual disabilities from the perspective of a novice researcher from outside the field of intellectual disabilities.

\section{Implications for practice}

- The experiences and perspectives of people with intellectual disabilities are needed to inform an inclusive evidence base in health research.

- IPA was a creative, flexible and person-centred methodology to employ with people with intellectual disabilities.

- Nurses should question healthcare research studies that do not include people with intellectual disabilities.

- With careful planning and adaptation, nurses can and should include research participants from hidden and hard to reach groups, such as people with intellectual disabilities. 


\section{References}

Barr, O., Gates, B., Mafuba, K. and Mitchell, D. (2019) Research and intellectual disability. Chapter 14. In Barr, O. and Gates, B. (2019) Oxford Handbook of Learning and Intellectual Disability Nursing. Second edition. Oxford: Oxford University Press.

Bigby, C., Frawley, P. and Ramcharan, P. (2014) 'Conceptualising inclusive research with people with intellectual disabilities'. Journal of Applied Research in Intellectual Disabilities. 27 pp 3-12.

Braun, V., and Clarke, V. (2013) Successful Qualitative Research a practical guide for beginners. London: Sage.

Burke, E., Carroll, R., O'Dwyer, M., Walsh, J.B., McCallion P., and McCarron., M. (2019) 'Quantitative examination of the bone health status of older adults with intellectual and developmental disability in Ireland: a cross-sectional nationwide study'. British Medical Journal Open. 2019;9:e026939. doi:10.1136/bmjopen-2018026939.

Crook, B., Tomlins, R., Bancroft, A., et al. (2015) 'So often they do not get recruited: exploring service user and staff perspectives on participation in learning disability research and the barriers that inhibit it'. British Journal of Learning Disabilities. 44, pp130-137. 
Department of Health and Social Care (2019) 'Right to be heard': The Government's response to the consultation on learning disability and autism training for health and care staff. Available via

https://assets.publishing.service.gov.uk/government/uploads/system/uploads/attach ment data/file/844356/autism-and-learning-disability-training-for-staff-consultationresponse.pdf

Accessed 24.10.2020.

Eatough, V., and Smith, J.A. (2006) 'I feel like a scrambled egg in my head: An idiographic case study of meaning making and anger using interpretative phenomenological analysis'. Psychology and Psychotherapy: Theory, Research and Practice. 79, pp 115-135.

Emerson, E., and Baines, S. (2011) 'Health inequalities and people with learning disabilities in the UK'. Tizard Learning Disability Review. 16, pp 42-48.

Equality Act (2010) Available via https://www.legislation.gov.uk/ukpga/2010/15 Accessed: 25 October 2020. 
Finlay, L. (2011) 'Interpretative Phenomenological Analysis' in Findlay, L. (2011) Phenomenology for Therapists: Researching the lived world. Chichester: WileyBlackwell.

Finlayson, J., Morrison, J., Jackson, A., Mantry, D., and S.-A. Cooper, S.-A. (2010) 'Injuries, falls and accidents among adults with intellectual disabilities. Prospective cohort study'. Journal of Intellectual Disability Research. doi: 10.1111/j.13652788.2010.01319.x 54, 11: 966-980.

Finlayson, J. (2011) Injuries, Accidents and Falls in Adults with Learning Disabilities and Their Carers: A Prospective Cohort Study (Ph.D. thesis). University of Glasgow.

Finlayson, J., Morrison, J., Skelton, D.A., Ballinger, C., Mantry, D., Jackson, A., and Cooper, S-A. (2014) 'The circumstances and impact of injuries on adults with learning disabilities'. The British Journal of Occupational Therapy. 77 (8), pp 400-409.

García Iriarte, E., O'Brien, P., and Chadwick, D. (2014) Involving People With Intellectual Disabilities Within Research Teams: Lessons Learned from an Irish Experience. Journal of Policy and Practice in Intellectual Disabilities, 11(2), 149-157. 
Gibbs, M., and Read, S.C. (2010) 'Involving people with intellectual disabilities in research: participation and emancipation' in Roberts, P.M., Priest, H.M., editors. Healthcare research: a handbook for students and practitioners. London: Wiley.

Gilbert, T. (2004) 'Involving people with learning disabilities in research: Issues and Possibilities'. Health \& Social Care in the Community. 12 (4), pp 298-308.

Goldsmith, L., and Skirton, H. (2015) Research involving people with a learning disability - methodological challenges and ethical considerations. Journal of Research in Nursing. 20 (6) pp 435-446.

Herron, D., Priest, H., and Read, S. (2015) 'Working alongside older people with a learning disability: Informing and shaping research design'. British Journal of Learning Disabilities. 43, pp 261-269.

Heslop, P., Blair, P., Fleming, M., et al. (2013) Confidential Inquiry into premature deaths of people with learning disabilities (CIPOLD). Bristol. Available at: http://www.bris.ac.uk/cipold/reports/index.html.

Accessed: $3^{\text {rd }}$ April, 2020.

Hollins, S., Carpenter, B., Bradley, E and Egerton, J. (2017) 'Using wordless books to support clinical consultations'. The Journal of Mental Health Training, Education and Practice, Vol. 12 Issue: 4, pp.260-271. 
lacono, T., Bigby, C.,Unsworth, C., Douglas, J. and Fitzpatrick, P. (2014) 'A systematic review of hospital experiences of people with intellectual disability'. Biomedical Central (BMC) Health Services Research. 14, pp 505 http://www.biomedcentral.com/1472-6963/14/505 Accessed: 24 July 2018.

Kinnear, D., Morrison, J., Allan, L., et al. (2018) 'Prevalence of physical conditions and multimorbidity in a cohort of adults with intellectual disabilities with and without Down syndrome: cross sectional study'. British Medical Journal Open. 2018;8:e018292. doi:10.1136/BMJ open-2017-018292.

Larkin, M., and Thompson, A. (2012) 'Interpretative phenomenological analysis' in Thompson and Harper (eds), Qualitative research methods in mental health and psychotherapy: a guide for students and practitioners. Oxford: John Wiley and Sons, $99-116$.

Llewellyn, P., and Northway, R. (2008) 'The views and experiences of people with intellectual disabilities concerning advocacy: A focus group study'. Journal of Intellectual Disability Research. 12 (3), pp 213-228.

Manning, C. (2009) ‘My Memory’s Back! Inclusive Learning Disability Research Using Ethics, Oral History and Digital Storytelling'. British Journal of Learning Disabilities. 38 pp 160-167.

McCarthy, M. (1998) 'Interviewing people with learning disabilities about sensitive 
topics: A discussion of ethical issues'. British Journal of Learning Disabilities. 26 (4), pp 140-145.

McCormack, B., and McCance, T. (2010) Person-Centred Nursing. Theory and Practice. Oxford: Wiley-Blackwell.

Mencap (2007) Death by Indifference. London: Mencap.

Mencap (2016) The Hospital Communication Book. London: Mencap.

Michael, J. (2008) Healthcare for all: report of the independent inquiry into access to healthcare for people with learning disabilities. London. Available via:

https://webarchive.nationalarchives.gov.uk/20130105064250/http://www.dh.gov.uk/e n/Publicationsandstatistics/Publications/PublicationsPolicyAndGuidance/DH 099255 Accessed: 24 October 2020.

National Health Service England (2017) Helping people with a learning disability to give feedback. London: NHS England.

National Health Service England (2020) The Learning Disabilities Mortality Review (LeDeR) Programme. Annual Report 2019. University of Bristol Norah Fry Centre for Disability Studies: NHS England. 
Nicholson, L., Colyer, M., and Cooper, S.-A. (2013) 'Recruitment to intellectual disability research: a qualitative study'. Journal of Intellectual Disability Research. 57, pp 647-656.

Nind, M., and Vinha, H. (2014) 'Doing research inclusively: bridges to multiple possibilities in inclusive research'. British Journal of Learning Disabilities. 42 (2), pp: $102-9$

Northway, R. (2000) 'The relevance of participatory research in developing nursing's research and practice'. Nurse Researcher. 7 pp 40-52 .

Northway, R., Howarth, J. and Evans, L. (2014) 'Participatory research, people with intellectual disabilities and ethical approval: Making reasonable adjustments to enable participation'. Journal of Clinical Nursing 24 (3-4).

Nuwagaba, E.L., and Rule, P. (2015) 'Navigating the ethical maze in disability research: ethical contestations in an African context'. Disability \& Society, 30 (2), pp 255-269.

Pietkiewicz, I., and Smith, J. (2012) 'A practical guide to using interpretative phenomenological analysis in qualitative research psychology'. Psychological Journal. 20 (1), pp 7-14.

Ravitch, S.M., and Riggan, M. (2017) Reason \& Rigor. How Conceptual Frameworks Guide Research. Second edition. London: Sage Publications Ltd. 
RCN (2017) The Needs of People with learning disabilities. What pre-registration students should know. London: RCN.

Royal College of Nursing (2019) A Competence Framework for Orthopaedic and Trauma Practitioners. London: RCN.

Silverman, D. (2011) Qualitative Research. Third edition. London: Sage.

Smith, J.A., Flowers, P., and Larkin, M. (2009) Interpretative Phenomenological Analysis. Theory, Method and Research. London: Sage.

Smith J. A., and Osborne M. (2008) 'Interpretative phenomenological analysis' in Smith, J. (ed.) Qualitative Psychology: A Practical Guide to Research Methods. London: Sage, pp 53-80.

Srikanth, R., Cassidy, G., Joiner, C., and Teeluckdharry, S. (2011) 'Osteoporosis in people with Intellectual disabilities: a review and a brief study of risk factors for osteoporosis in a community sample of people with intellectual disabilities'. Journal of Intellectual Disability Research. 55, pp 53-62.

Sydor, A. (2013) 'Conducting research into hidden or hard to reach populations'. Nurse Researcher. 20 (3), pp 33-37. 
Tajuria, G., Read, S., and Priest, H.M. (2017) 'Using Photovoice as a method to engage bereaved adults with intellectual disabilities in research: listening, learning and developing good practice principles'. Advances in Mental Health and Intellectual Disabilities. 11 (5/6), pp 196-206.

United Nations (2006) Convention on the Rights of Persons with Disabilities. Geneva: UN. Available via

https://www.un.org/development/desa/disabilities/convention-on-the-rights-ofpersons-with-disabilities.html

Accessed: 24.10.2020.

Walmsley, J., Strnadova, I., and Johnson, K. (2018) 'The added value of inclusive research'. Journal of Applied Research in Intellectual Disabilities. 31 (5), pp 751-759. 